\title{
Description of the aberrant Leptopilina Iasallei n. sp., with an updated phylogeny of Leptopilina Förster (Hymenoptera: Figitidae: Eucoilinae)
}

\author{
Matthew L. Buffington, Massimo Giorgini , Chia-Hua Lue , Giorgio
} Formisano , Pasquale Cascone, Mattias Forshage , Amy Driskell \& Emilio Guerrieri

To cite this article: Matthew L. Buffington , Massimo Giorgini , Chia-Hua Lue , Giorgio Formisano , Pasquale Cascone, Mattias Forshage , Amy Driskell \& Emilio Guerrieri (2020) Description of the aberrant Leptopilina lasallei n. sp., with an updated phylogeny of Leptopilina Förster (Hymenoptera: Figitidae: Eucoilinae), Journal of Natural History, 54:9-12, 565-583, DOI: 10.1080/00222933.2020.1754483

To link to this article: https://doi.org/10.1080/00222933.2020.1754483

Џ Article views: 55

Q View related articles $\longleftarrow$

View Crossmark data $\asymp$ 


\section{Description of the aberrant Leptopilina lasallei $\mathrm{n}$. sp., with an updated phylogeny of Leptopilina Förster (Hymenoptera: Figitidae: Eucoilinae)}

Matthew L. Buffington (ID ${ }^{a}$, Massimo Giorgini $\left(D^{b}{ }^{b}\right.$, Chia-Hua Lue ID $^{c, d}$, Giorgio Formisano ${ }^{b}$ Pasquale Cascone ${(\mathbb{D})^{b}}^{b}$, Mattias Forshage ${ }^{e}$, Amy Driskell ${ }^{f}$ and Emilio Guerrieri $\mathbb{D}^{\mathrm{b}, \mathrm{g}}$

aSystematic Entomology Laboratory, ARS/USDA c/o Smithsonian Institution, National Museum of Natural History, Washington, DC, USA; ' Institute for Sustainable Plant Protection, National Research Council of Italy, Portici, Italy; 'Department of Biological Sciences, University of Maryland Baltimore County, Baltimore, MD,

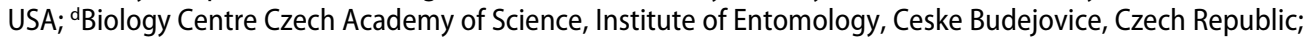
eDepartment of Zoology, Swedish Museum of Natural History, Stockholm, Sweden; fLaboratories of Analytical Biology, Smithsonian Institution, National Museum of Natural History, Washington, DC, USA; 9Department of Life Sciences, The Natural History Museum, London, UK

\begin{abstract}
In the search for native Asian parasitoids of Drosophila suzukii, the notorious spotted-wing Drosophila (SWD), an odd new species of Eucoilinae was discovered. Leptopilina lasallei sp. nov. is herein described and diagnosed relative to other eucoilines associated with drosophilid hosts. Morphologically, L. lasallei is somewhat aberrant within Leptopilina; phylogenetically, L. Iasallei is sister group to the core Leptopilina. In the process of investigating $L$. lasallei, a de novo molecular phylogeny of Leptopilina was generated and is included here. The integrated approach used for the characterisation of $L$. lasallei, and the resulting phylogeny of Leptopilina, produced data useful to select parasitoid species for SWD biological control.

http://www.zoobank.org/urn:Isid:zoobank.org:act:402D504A-4616-4524-85D7-1C13A6276F06 http://www.zoobank.org/urn:Isid:zoobank.org:act:402D504A-4616-4524-85D7-1C13A6276F06
\end{abstract}

\section{ARTICLE HISTORY}

Received 7 October 2019

Accepted 16 March 2020

Published online 23

September 2020

Published in print 23

September 2020

\section{KEYWORDS}

Drosophilidae; Eucoilini; Trybliographa; COI; D2-28S and ITS2 genes; Bayesian phylogenetic analysis; spotted-wing Drosophila

Species of Leptopilina (Hymenoptera: Figitidae: Eucoilinae), parastioids of drosophilid flies (Diptera), have been studied in laboratory settings for decades. These wasps are easily cultivated into lab strains, which are studied in captivity for research ranging from host resistance (e.g. Vass and Nappi 2000; Lee et al. 2009) to host-finding cues (e.g. Van Alphen et al. 1991). Understanding the taxonomy and evolutionary history of Leptopilina species has been the focus of research since Nordlander's (1980) groundbreaking work on the genus. Since then, several new species have been described in the genus (Novković et al. 2011; Wachi et al. 2015; Lue et al. 2016), and several phylogenies have been published (Schilthuizen et al. 1998; Allemand et al. 2002; Novković et al. 2011; Wachi et al. 2015). Collectively, we know more about the systematics of this genus than most other Eucoilinae, and this has benefitted efforts to locate parasitoids of the notorious spottedwing Drosophila, Drosophila suzukii (Matsumura, 1931) (Diptera: Drosophilidae) (SWD). 
Several species of Leptopilina have been implicated as natural enemies of SWD. This pest fly is established in all soft-fruit growing regions of the United States, as well as Mexico, Canada, parts of Central and South America, and Europe. Spotted-wing Drosophila has a wide host range in its native home (Asia) and invaded countries where it feeds on numerous soft fruits (e.g. strawberry, caneberry, blueberry and cherry), using a serrated ovipositor to tear open and lay several eggs within each fruit; the eggs hatch and the developing larvae feed within the fruit with little to no external evidence of damage. Since 2008, when SWD was first recognised as a major pest in North America, hundreds of millions of dollars in production loss due to SWD (as well as to mitigation of SWD) occurred in California alone (Farnsworth et al. 2017). Including the East Coast fruitgrowing region of the United States, as well as soft-fruit production in Canada, Mexico and Europe, could triple that number.

The search for effective natural enemies of this pest fly has been the focus of a great deal of research in recent years (Daane et al. 2016; Guerrieri et al. 2016; Nomano et al. 2017; Girod et al. 2018; Giorgini et al. 2019). This exploration in Asia for natural enemies of SWD has identified 5-7 species of Leptopilina and Ganaspis (Figitidae), Asobara (Braconidae) (larval parasitoids) and Pachycrepoides (Pteromalidae) and Trichopria (Diapriidae) (pupal parasitoids) (see Giorgini et al. 2019).

In the pursuit of these natural enemies, an unidentified figitid wasp was recovered in consistent quantities from banana-baited traps in Yunnan Province, China, totalling 11\% of all collected parasitoids and about $30 \%$ of all collected figitids (referred to as 'new genus' in Giorgini et al. 2019); the same species was reared from Myrica rubra infested with Drosophila suzukii and D. pulcrhella (referred to as 'Leptopilina sp.' in Girod et al. 2018). The species did not match any description in Lin (1988) or Lee and Choi (1993); the species initially looked similar to Leptopilina decemflagella Lue and Buffington, but lacked a number of characters present in that species. Additional Leptopilina material has been examined and compared to this new taxon from the Taiwanese Agriculture Research Institute (TARI, Taichung, Taiwan; major depository of the Lin Collection; Lin, 1988) and the Bernice P. Bishop Museum (BPBM, Honolulu, HI; major depository of the Maa and Yoshimoto cynipoid collections (Yoshimoto, 1962; Yoshimoto and Yasumatsu, 1965)), as well as further comparison with specimens housed at the National Museum of Natural History, Smithsonian Institution, Washington DC (USNM); however, none of these collections had specimens conspecific with this unknown wasp.

The combination of morphological and molecular data clarified the identity of this new species discovered in Yunnan Province, China, which is herein described as Leptopilina lasallei Buffington and Guerrieri, sp. nov. While pursuing the phylogenetic placement of $L$. lasallei, we generated an updated phylogeny of Leptopilina and discuss the relationships therein.

\section{Materials and methods}

\section{Field collections}

Surveys for Drosophila parasitoids were conducted between 2013 and 2016 in different locations of Yunnan Province, China (see material examined for details), using bananabaited traps placed in natural vegetation or cultivated fields, or collections of berries from 
natural vegetation (see Giorgini et al. 2019). Banana-baited traps were made from plastic food boxes $(10 \times 15 \times 30 \mathrm{~cm})$ with $0.5-\mathrm{cm}$ holes along the side for ventilation and provisioned with sliced sections of banana for fruit fly egg deposition (developing into fresh larvae available for parasitisation). At each of the sampled sites, 4-11 traps were placed in a linear transect at distances of $\sim 100 \mathrm{~m}$ from each other. After 7 days, traps were collected and transferred to a laboratory (Yunnan Academy of Agricultural Science), where the ventilation holes were covered with organdie and the traps were held at $25 \pm 3^{\circ} \mathrm{C}, 65 \pm 5 \%$ relative humidity, $12 \mathrm{~L}: 12 \mathrm{D}$ photoperiod and observed daily for fly or parasitoid emergence. Field-collected fruits were placed into aerated boxes under the same conditions as described above and observed daily for parasitoid emergence. Emerged parasitoids were collected and immediately killed in 95\% ethanol and preserved at $-20^{\circ} \mathrm{C}$ until identification.

\section{Integrated characterisation of insects}

An integrated approach was followed to describe the new species by combining morphological and molecular diagnostic data.

\section{Morphological examination and description}

The diagnosis, description and morphological terms are derived from Lue et al. (2016). Specimens used in this study were dry mounted (using a vacuum dryer; Gates and Buffington 2011) for long-term preservation and examined in the Hymenoptera Unit at USNM. Morphological structures of insects were observed using a Leica M205 c binocular stereomicroscope with fluorescent light sources. Diagnostic characters for each species were illustrated using a scanning electron microscope (SEM; Hitachi ${ }^{\oplus \mathrm{TM}} \mathrm{TM} 3000$ ) and a Macropod ${ }^{\circledR \mathrm{TM}}$ multiple-focus imaging system. For SEM images, vacuum-dried samples were mounted to adhesive SEM stubs and sputter-coated with gold-palladium for a 240-s interval resulting in 25$30 \mathrm{~nm}$ of gold-palladium alloy (using a Cressington ${ }^{\oplus \mathrm{TM}} 108$ Autosputtercoater). Zerene Stacker ${ }^{\circledast \mathrm{TM}}$ was used to make composite images from image stacks generated by the Macropod.

\section{Molecular characterisation}

Newly field-collected wasps were sequenced for the mitochondrial barcoding cytochrome oxidase subunit 1 (COI) gene region, the ribosomal 28S-D2 region, and the Internal Transcribed Spacer 2 (ITS2) region.

DNA was extracted using a non-destructive whole-specimen extraction Chelexproteinase $\mathrm{K}$ protocol (e.g. Guerrieri et al. 2016). Polymerase chain reactions (PCR) were performed in $20 \mu \mathrm{L}$ volumes containing $4 \mu \mathrm{L}$ of $1 \mathrm{X}$ GoTaq buffer (Promega Corp., Madison, Wisconsin, USA), $1.6 \mu \mathrm{L}$ dNTP (2.5 mM each), $1 \mu \mathrm{L}$ of forward and reverse primer (10 $\mu \mathrm{M}$ each), $0.4 \mu \mathrm{L}$ GoTaq G2 DNA Polymerase (Promega) $(5 \mathrm{u} / \mu \mathrm{L})$ and $2 \mu \mathrm{L}$ template DNA. Amplifications were achieved using a Bio-Rad Mycycler thermocycler (Bio-Rad, Hercules, California, USA) programmed for 1 min at $94^{\circ} \mathrm{C}$, followed by 40 cycles of $30 \mathrm{~s}$ at $94^{\circ} \mathrm{C}, 90 \mathrm{~s}$ at $48^{\circ} \mathrm{C}$ and $60 \mathrm{~s}$ at $72^{\circ} \mathrm{C}$, and a final step of $7 \mathrm{~min}$ at $72^{\circ} \mathrm{C}$. Amplification of the mitochondrial $\mathrm{COI}$ gene was performed using one of the following primer combinations: LCO and HCO (Folmer et al. 1994) or 
LepF1 and LepR1 (Hebert et al. 2004). The thermocycler was set at $94^{\circ} \mathrm{C}$ for $1 \mathrm{~min}$, followed by 40 cycles at $94^{\circ} \mathrm{C}$ for $30 \mathrm{~s}, 48^{\circ} \mathrm{C}$ for $90 \mathrm{~s}$ and $72^{\circ} \mathrm{C}$ for $60 \mathrm{~s}$, and at $72^{\circ} \mathrm{C}$ for $7 \mathrm{~min}$ as the final step.

Amplification of the 28S-D2 ribosomal gene region was performed using the primer combination D2 F and D2Ra (Campbell et al. 2000). The thermocycler was set at $94^{\circ} \mathrm{C}$ for $3 \mathrm{~min}$, followed by 35 cycles at $94^{\circ} \mathrm{C}$ for $45 \mathrm{~s}, 55^{\circ} \mathrm{C}$ for $45 \mathrm{~s}$ and $72^{\circ} \mathrm{C}$ for $45 \mathrm{~s}$, and at $72^{\circ} \mathrm{C}$ for $7 \mathrm{~min}$ as the final step.

Amplification of the ITS2 region was performed using the primer combination ITS2 $\mathrm{F}$ and ITS2revb (Stouthamer et al. 1999). The thermocycler was set at $94^{\circ} \mathrm{C}$ for $1 \mathrm{~min}$, followed by 35 cycles at $94^{\circ} \mathrm{C}$ for $45 \mathrm{~s}, 55^{\circ} \mathrm{C}$ for $60 \mathrm{~s}$ and $72^{\circ} \mathrm{C}$ for $60 \mathrm{~s}$, and at $72^{\circ} \mathrm{C}$ for $7 \mathrm{~min}$ as the final step.

PCR products were visualised after electrophoresis on $1 \%$ agarose gel stained with Gel Red ${ }^{\mathrm{TM}}$ (Biotium Inc, Fremont, California, USA) to confirm the amplification. Fragments obtained were sequenced in both sense and antisense directions by adopting EZ-seq standard service (Macrogen Inc., Seoul, South Korea). The chromatograms obtained were viewed and edited in Chromas v. 2.6.4 (Technelysium, South Brisbane, Queensland, Australia). Protein-coding of the COI gene region was checked by translating the sequences into amino acids, and no evidence for the presence of pseudogenes (i.e. no stop codons or frame shifts) was detected. All sequences were deposited in GenBank under the accession numbers reported in Table 1, and parasitoid wasps were vouchered at the USNM. Other taxa used in this study were previously sequenced by our group at the USNM (see Table 1 for details) following the protocols reported in Lue et al. (2016).

\section{Phylogenetic reconstruction}

Sequences not generated de novo in this study were taken from Lue et al. (2016), and previous studies where vouchers of sequenced individuals could be examined (Table 1). Alignment of concatenated COI, 28S-D2 and ITS2 sequenced regions were examined in Mesquite 3.5 (Maddison and Maddison 2019) and verified by eye for errors. The 28S D2 fragment was compared to the Buffington et al. (2007) structural alignment. As these species are all within Eucoilini sensu Forshage (2008), alignment was uncontroversial. The resulting concatenated matrix of COI, 28S-D2 and ITS2 was exported from Mesquite for Mr. Bayes 3.2, applying the GTR+I + G rate matrix for each data partition ( $\mathrm{CO}$ divided into three partitions, one for each position) and running 15 million generations with a burn-in of 25\%; explanation and justification of these protocols are provided in Buffington et al. (2007). The resulting tree was visualised in FigTree 1.3.1, and the out-group (Trybliographa) was assigned; the final tree figure was generated using Adobe Illustrator. 


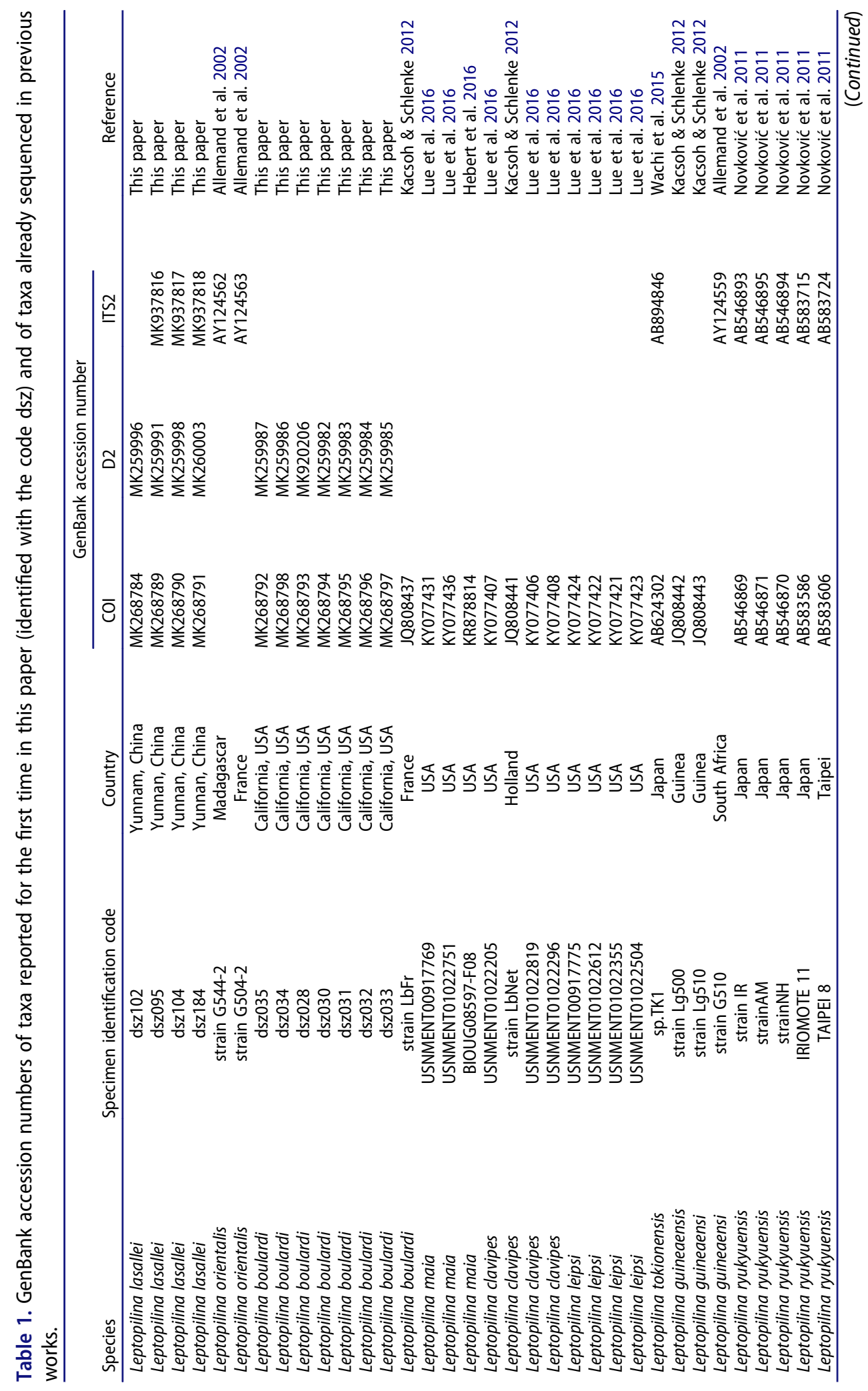




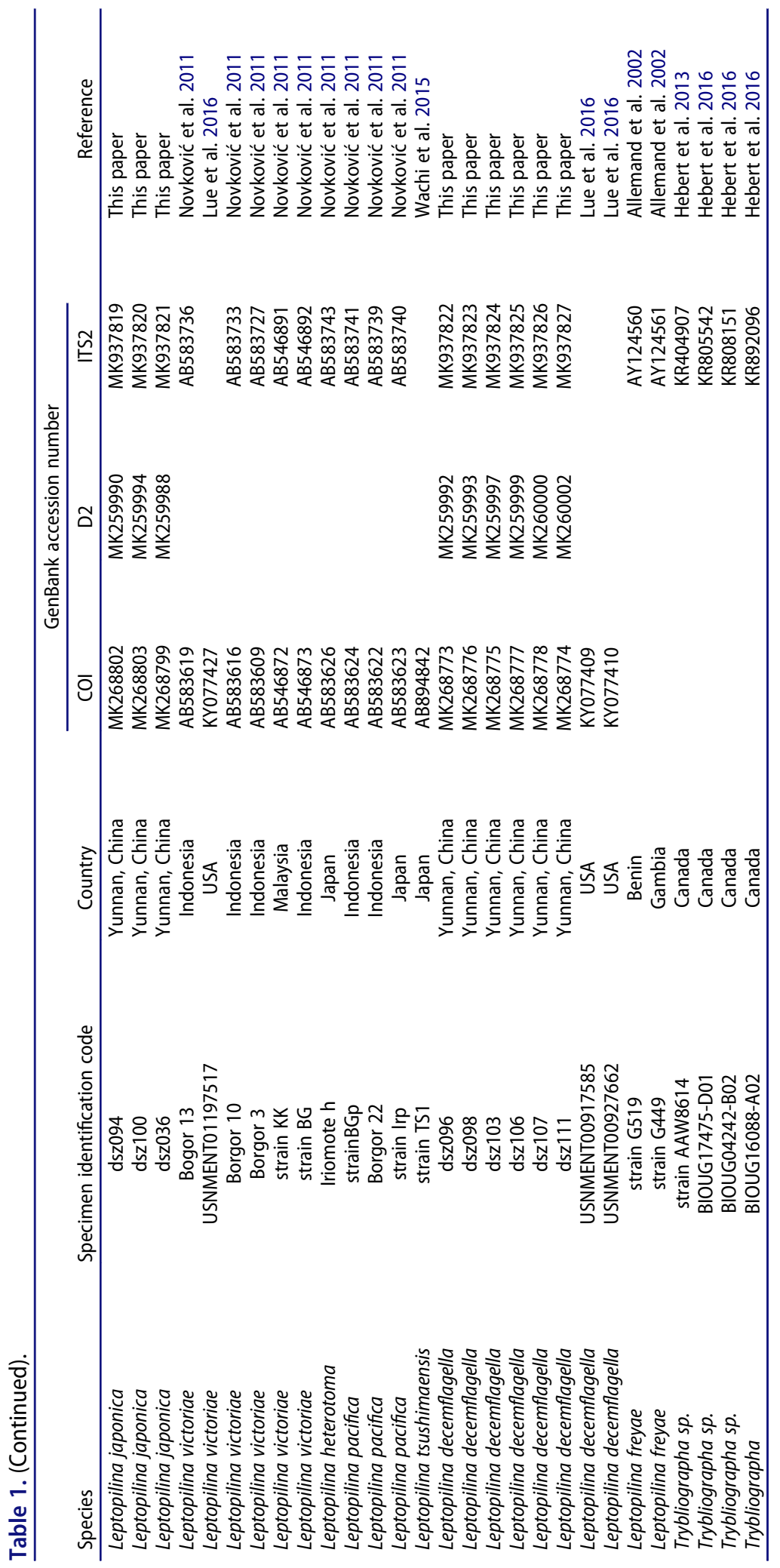


Table 2. Summary of diagnostic characters for separating L. lasallei from other eucoilines of similar habitus and habitat.

\begin{tabular}{|c|c|c|c|c|}
\hline \multirow[b]{2}{*}{ Character } & \multicolumn{4}{|c|}{ Genus } \\
\hline & Leptopilina Iasallei & Other Leptopilina & Ganaspis & Hexacola \\
\hline Female petiole & As deep as long & $\begin{array}{l}\text { As deep as or deeper } \\
\text { than long }\end{array}$ & As deep as long & As deep as long \\
\hline $\begin{array}{l}\text { Setal band at base of } \\
\text { female metasoma }\end{array}$ & Complete & $\begin{array}{l}\text { Interrupted dorsally or } \\
\text { largely incomplete }\end{array}$ & Complete & Complete \\
\hline $\begin{array}{l}\text { Posteroventral corner of } \\
\text { female metapleuron }\end{array}$ & Glabrous & Glabrous & Setose & Setose \\
\hline $\begin{array}{l}\text { Number of flagellomeres in } \\
\text { female antenna }\end{array}$ & 10 & 10 or 11 & 11 & 11 \\
\hline Length of male antenna F2 & As long as F1 & As long or longer than F1 & Shorter than F1 & Shorter than F1 \\
\hline Dorsal surface of scutellum & Striate & Striate to rugulose & Rugulose & Striate \\
\hline
\end{tabular}

\section{Results}

\section{Morphological description}

\section{Leptopilina Iasallei Buffington and Guerrieri sp. nov.}

(Figures 1-4)

\section{Diagnosis}

Female. Setal band complete at base of metasoma (Figures $1 \mathrm{~b}$ and Figure 2e); dorsal surface of scutellum anteriorly striate, posteriorly foveate (Figure 2f); posteroventral corner of metapleuron glabrous (Figure 2e); antenna with 10 flagellomeres (Figure 2c); petiole as long as wide (Figure 2e). Male similar to female except setal band incomplete at base of metasoma (Figure 3a); antenna with 13 flagellomeres (Figure 3a), F1 the same size as F2, not distinctly excavated laterally (Figure 3b). See Table 2 for a summary of characters.

\section{Description}

Female. Holotype length $1.4 \mathrm{~mm}$.

General. Body overall very smooth, glabrous, lacking sculpture except on scutellum (Figures 1 and 3). Head, mesosoma, metasoma dark brown, wings hyaline, legs honey yellow.

Head. In anterior view, ovate (Figure 2a). Head glabrous with very sparse setae scattered on face, clypeus and mandibles. Lateral margin of occiput smooth. Ratio of length of gena (I, Figure 2a) to length of compound eye (II, Figure 2b) 1 to 3. Gena smooth. Lateral margin of occiput evenly rounded, not well defined. Occiput smooth. Ratio of maximum diameter of a lateral ocellus (III, Figure 2b) to shortest distance between lateral ocelli (IV, Figure 2b) $1: 2$. Posterior margin of anterior ocellus clearly separated from anterior margins of posterior ocelli. Ratio of vertical distance between inner margin of antennal foramen and ventral margin of clypeus (V, Flgure 2a) to vertical distance between anterior ocellus and antennal rim (VI, Figure 2a) 1:4. Median keel absent. Vertical carina adjacent to ventral margin of 


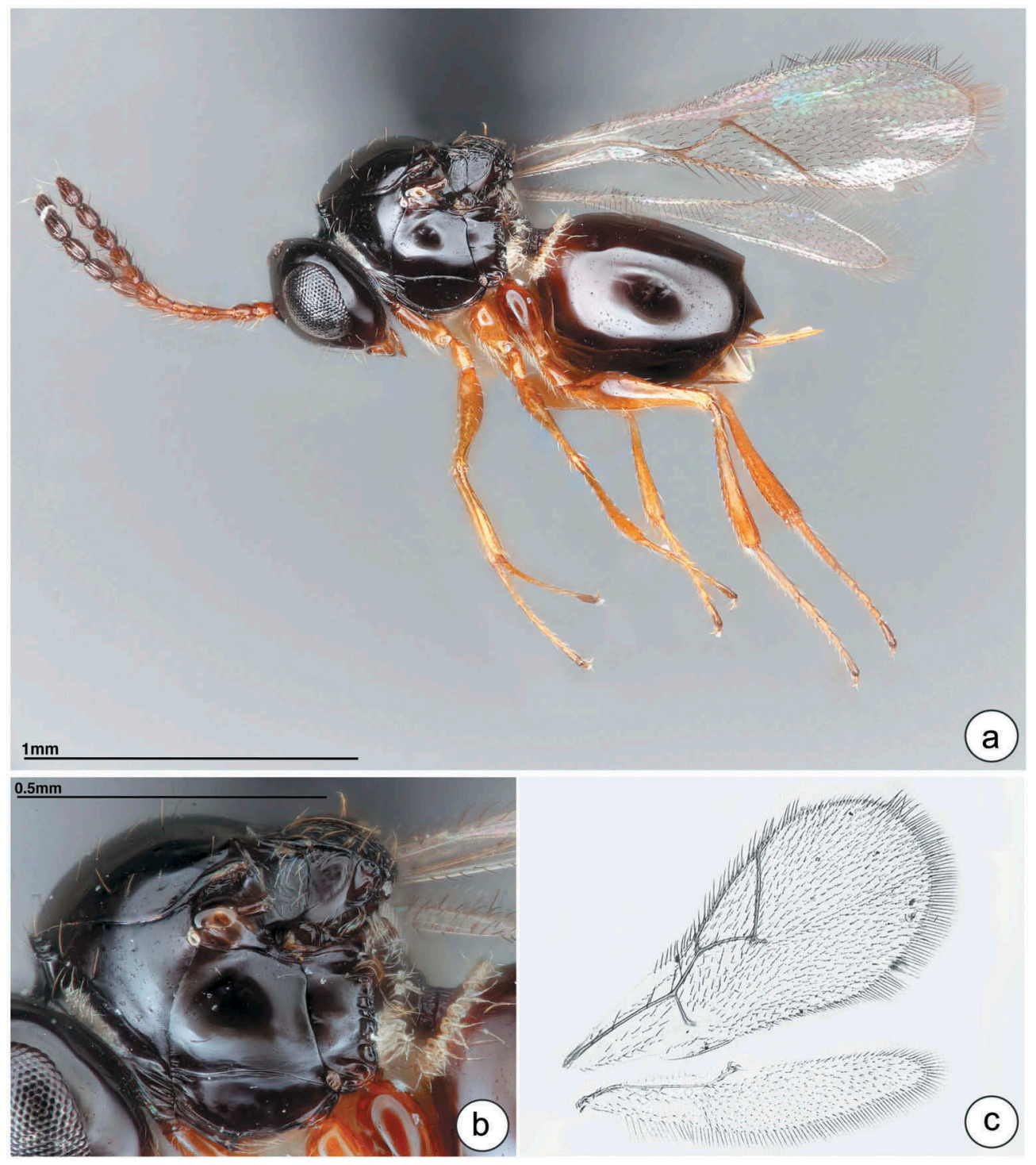

Figure 1. Holotype of Leptopilina lasallei sp. nov. (USNMENT00896641). a. Lateral habitus. b. Close-up of mesosoma. c. Left fore and hind wings.

antennal socket present, minute. Facial sculpture absent, surface smooth. Facial impression absent, face flat. Antennal scrobe absent. Anterior tentorial pits small (VII, Figure 2a). Vertical delineations on lower face absent. Ventral clypeal margin laterally, close to anterior mandibular articulation, straight. Ventral clypeal margin medially with 6 setae. Clypeus smooth with gently curved ventral margin. Malar space adjacent to anterior articulation of mandible evenly rounded, smooth. Malar sulcus (VIII, Figure 2a) present, simple. Ratio of distance between compound eye and posterior mandibular articulation to distance between posterior ocellus and compound eye 1:1. Compound eyes, in dorsal view, not distinctly protruding from the surface of the head (Figure 2). Short, sparse setae 
on eyes (Figure 2). Orbital furrows absent. Lateral frontal carina of face absent. Dorsal and posterior aspects of vertex smooth. Hair punctures on lateral aspect of vertex absent. Posterior surface of head deeply impressed around postocciput.

Labial-maxillary complex. Apical segment of maxillary palp with pubescence, consisting of 1 long erect seta. Apical seta on apical segment of maxillary palp longer than twice length of second longest apical seta. Maxillary palp composed of 4 segments. Last 2 segments of maxillary palp (in normal repose) straight. Apical segment of maxillary palp $2 \mathrm{X}$ longer than preceding segment.

Antenna. Terminal flagellomere with 3 basiconic sensillae. Basiconic sensillae present on F5-F9. Articulation between flagellomeres in antenna moniliform, segments distinctly separated by narrow neck-like articulation. Antenna composed of 10 flagellomeres (Figure 2c); F1 2.5X longer than F2. Flagellomeres cylindrical, distinctly widened towards apex, clavate. Placoidal sensilla present on F5-F10 (Figure 2c).

Mesosoma. Macrosculpture on lateral surface of pronotum absent dorsally and laterally (Figure 1). Anteroventral inflection of pronotum narrow. Pubescence on lateral surface of pronotum present in pronotal trough. Anterior flange of pronotal plate distinctly protruding anteriorly, transversely strigate (Figure 2). Ridges extending posteriorly from lateral margin of pronotal plate distinct but short, not extending to the dorsal margin of pronotum. Lateral pronotal carina absent. Crest of pronotal plate absent. Dorsal margin of pronotal plate (in anterior view) spatulate. Submedian pronotal depressions open laterally, deep (Figure 2). Lateral margin of pronotal plate defined all the way to the dorsal margin of the pronotum. Width of pronotal plate narrow, not nearly as wide as head.

Mesoscutal surface convex, evenly curved (Figure 1). Sculpture on mesoscutum absent, entire surface smooth, shiny, with sparse long hairs. Notauli absent. Median mesoscutal carina, anterior admedial lines and median mesoscutal impression all absent. Parascutal carina nearly straight.

Mesopleuron entirely smooth (Figure 1). Subpleuron entirely smooth, glabrous. Lower pleuron entirely smooth, glabrous. Epicnemial carina absent. Lateroventral mesopleural carina present, marking abrupt change in slope of mesopectus. Mesopleural triangle absent. Subalar pit present, located under subalar area, not easily observed. Speculum absent. Mesopleural carina present, complete, composed of one complete, uninterrupted carina. Anterior end of mesopleural carina inserting above notch in anterior margin of mesopleuron.

Dorsal surface of scutellum distinctly striate on anterior $2 / 3$, posterior $1 / 3$ foveate (Figure 2). Circumscutellar carina present, complete, delimiting dorsal and ventral halves of scutellum. Posterior margin of axillula marked by distinct ledge, axillula distinctly impressed. Lateroventral margin of scutellum posterior to axillula smooth. Dorso-posterior part of scutellum rounded. Transverse median carina on scutellar plate absent. Scutellar plate, in dorsal view, exposing more than half of scutellum. Scutellar fovea present, 2 , distinctly margined posteriorly, smooth on bottom. Longitudinal scutellar carinae absent. Single longitudinal carina separating scutellar foveae present, short, ending at posterior margin of foveae. Posterolateral margin of scutellum rounded. Lateral bar smooth, narrow. 

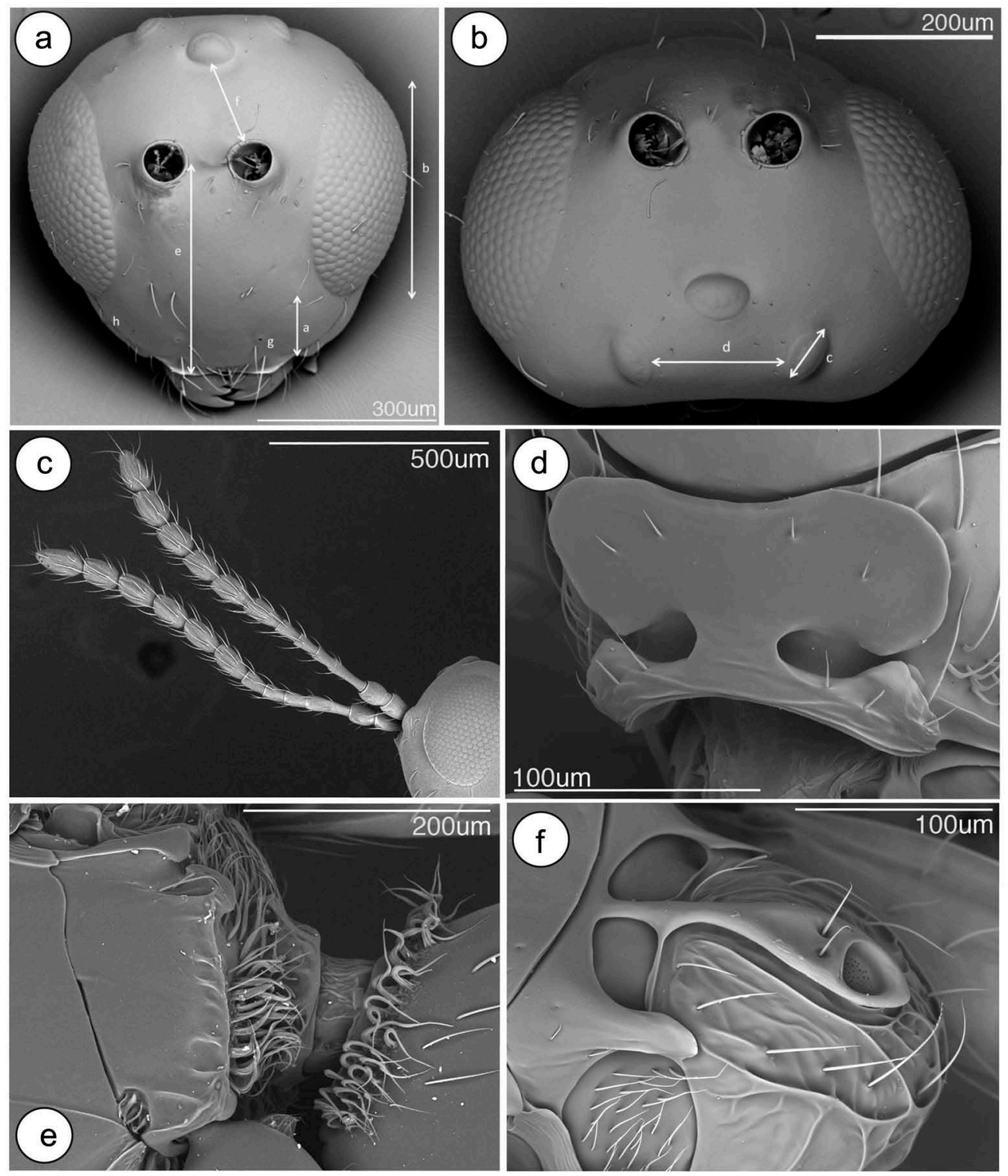

Figure 2. Scanning electron micrographs of the paratypes of Leptopilina lasallei sp. nov. (USNMENT01525765). a. Head, anterior view; I, distance from ventral margin of eye to posterior margin of malar space; II, height of eye; $\mathrm{V}$, distance between inner rim of torulus to posterior clypeal margin; Vl; distance between anterior ocellus and posterior rim of torulus; VII, tentorial pit; VIII, malar furrow. b. Head, dorsal view; III, width of lateral ocellus; IV, distance between lateral occeli. c. Female antenna, lateral view. d. Anterior aspect of pronotal plate, male. e. Close-up lateral aspect of metapleuron, propodeum, petiole and anterior margin of metasoma. f. Male scutellum, dorso-lateral view.

Metapleural-propodeal complex. Posterior impression of metepimeron absent (Figures 2 and 2e). Metapectal cavity anterodorsal to metacoxal base present, well defined. Anterior margin of metapectal-propodeal complex meeting mesopleuron at same level at point 


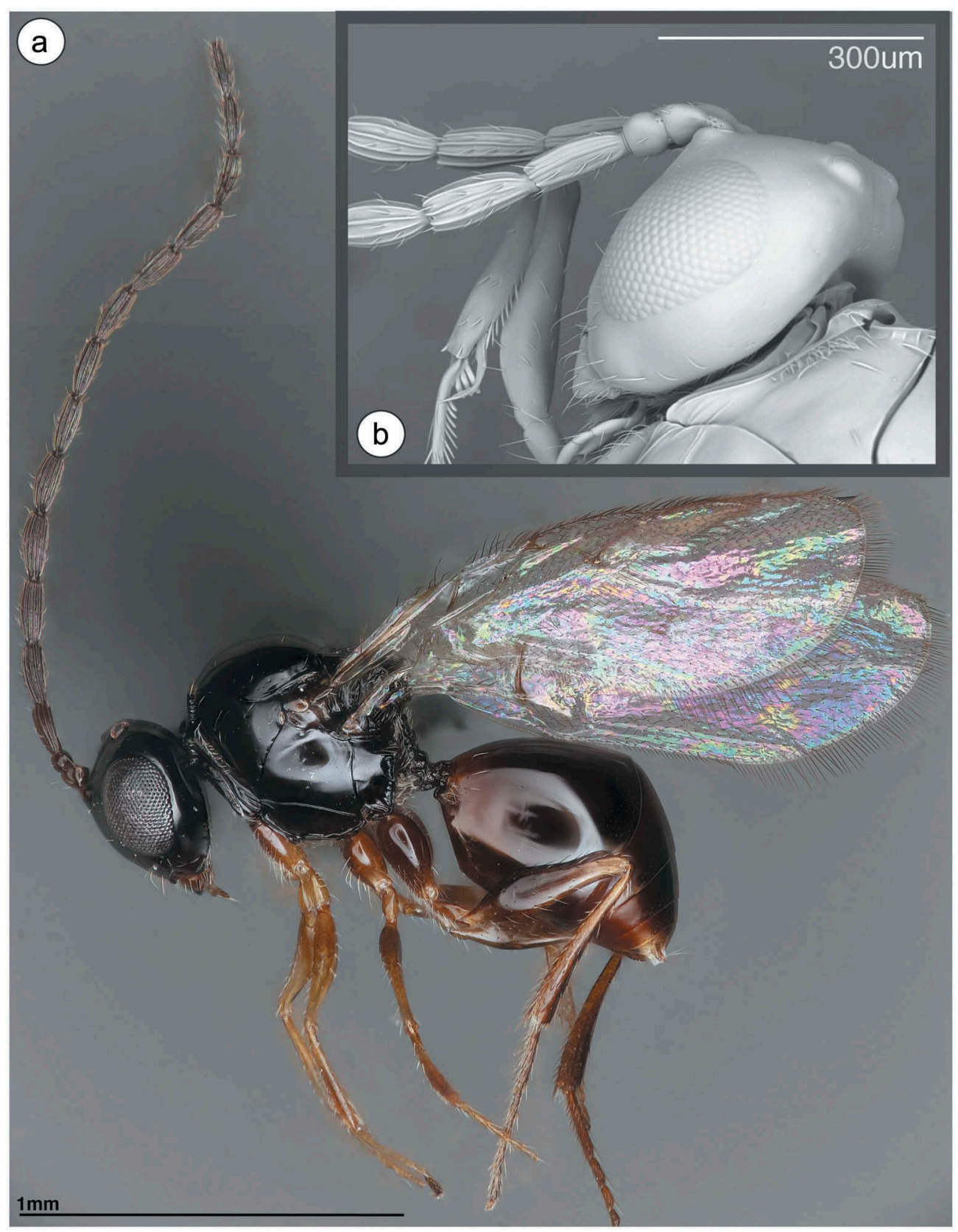

Figure 3. Male paratype. a. lateral habitus. b. Scanning electron micrograph of head and basal segments of antennae.

corresponding to anterior end of metapleural carina. Posteroventral corner of metapleuron (in lateral view) not extended posteriorly, glabrous. Anterior impression of metepimeron absent. Posterior margin of metepimeron distinct, separating metepimeron from propodeum. Subalar area broadened anteriorly, narrowed posteriorly. Prespiracular process present, blunt, lobe- 


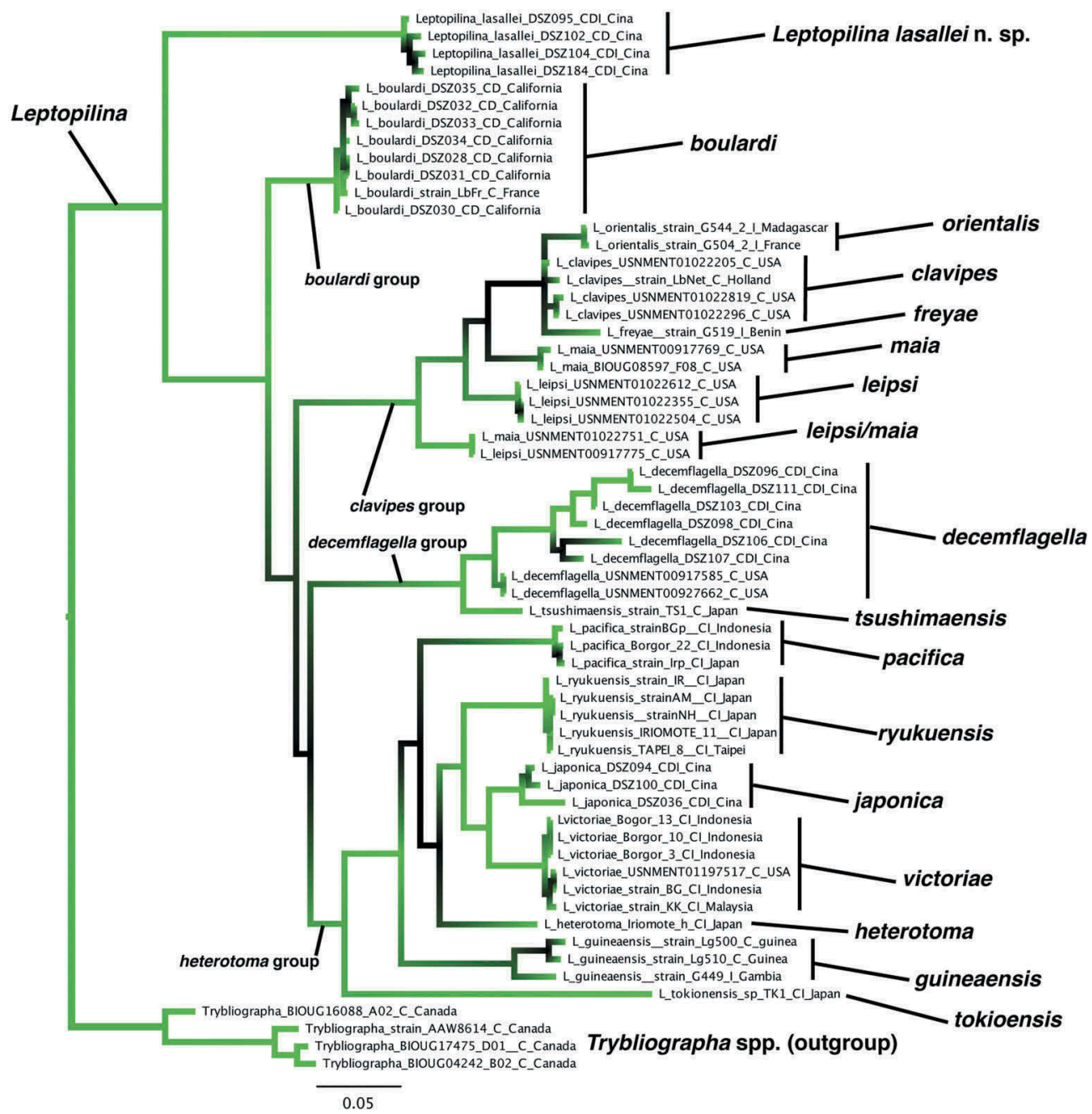

\section{0 posterior probability}

\section{5 posterior probability}

Figure 4. Phylogeny of Leptopilina based on Bayesian analysis of concatenated nucleotide sequences of Cytochrome Oxidase I (COI) gene 'barcode' region, 28S D2 and ITS2 regions. Taxa denoted by 'DSZ' are newly sequenced for this study; other number/letter designations are those of Genbank sequences. See Table 1 for GenBank accession numbers and references.

like, rough. Dorsellum absent. Anterior impression of metepisternum present. Pubescence consisting of few hairs on posterior part of metepisternum, dense hair on propodeum.

Propodeal spurs absent. Lateral propodeal carinae present, not reaching scutellum, lyre-shaped, stout. Ventral end of lateral propodeal carina reaching nucha, carinae separated from each other. Inter-propodeal carina space lightly setose, underlying surface smooth. Petiolar rim of uniform width along entire circumference. Petiolar foramen removed from metacoxae, directed posteriorly. Horizontal carina running anteriorly 
from lateral propodeal carina present medially, effaced laterally. Calyptra, in lateral view, rounded; in posterior view, elongate. Propodeum neck-like, drawn out posteriorly.

Legs. Pubescence posterolaterally on metacoxa, present, small, rounded, with adjacent sparse pubescence (Figure 1). Microsculpture on hind coxa absent. Longitudinal ridge on the posterior surface of metatibia absent. Metafemoral tooth present, elongate, with adjacent serrate ridge posteriorly. Ratio of first metatarsal segment to remaining 4 segments $2.1: 1$.

Wings. Wing vein $\mathrm{M}$ absent (Figure 3). Pubescence of fore wing present, long, dense on most of surface. Apical margin of fore wing rounded; Rs+M of fore wing defined but nebulous at point of origin from basal vein at posterior third; mesal end of Rs+M vein situated closer to anterior margin of wing, directed towards middle of basalis; vein R1 forming marginal cell completely; basal abscissa of R1 as broad as adjacent wing veins. Colouration of wing absent, entire wing hyaline. Marginal cell of fore wing membranous, similar to other wing cells. Areolet absent. Hair fringe along apical margin of fore wing present, of medium length.

Metasoma. Petiole about as long as wide (Figures 2). Surface of petiole longitudinally costate, ventral keel absent. Posterior part of petiole not abruptly widened. Ventral and lateral parts of petiolar rim broad. Setal band at base of tergum 3 present, uninterrupted dorsally and ventrally (Figures 1 and 2). Tergum 3 indistinct, fused with syntergum. Posterior margin of tergum 4 evenly rounded. Sternum 3 encompassed by syntergum. Sculpture on metasomal terga absent (Figure 1). Syntergum present with terga 3 to 5 fused, ventral margin rounded. Peglike setae on T6-T7 absent. Postero-ventral cavities of female metasoma T7 present, glabrous save for few, long setae. Female postero-ventral margin of T6-T7 straight, parallel. Terebrum and hypopygium (in lateral view) straight, pointing posteriorly. Ovipositor clip present.

Male: Similar to female except for antenna with 13 flagellomeres (Figure 2) with unmodified F2 (Figure 2), absence of setal band at base of tergum 3 (Figure 2). Metasoma, posteriorly, directly ventrally, somewhat truncate.

Variation. Body size ranges from 1.2 to $1.5 \mathrm{~mm}$. Overall body colouration varies slightly from dark brown to nearly black; dorsal surface of scutellum can range from slightly striate to deeply striate, foveate at posterior end of scutellum; very faint setal tracks present on the mesoscutum of some specimens, absent in others.

Etymology. Named in honour of the late Dr John La Salle. John's dedication to Hymenoptera research, and biodiversity research in general, will be greatly missed. We hope this honorific helps to keep his memory alive for years to come.

Material examined. Holotype:. , CHINA, Kunming, Xiao He Research Farm, Pan Long District $25.176593^{\circ} \mathrm{N}, 102.794697^{\circ} \mathrm{E}, 2209 \mathrm{~m}$ above sea level (asl), 20 July 2015, from banana trap, EGWY124 (Wang Yan) USNMENT00896641; left fore and hind wings mounted on slide USNMENT01525760. 
Paratypes: 1 , CHINA, Kunming, Xiao He Research Farm, Pan Long District $25.176593^{\circ} \mathrm{N}$, $102.794697^{\circ} \mathrm{E}, 2209 \mathrm{~m}$ asl, October 2014, from banana trap, EGWY36 (Wang Yan) USNMENT00896646; 1 , CHINA, Kunming, Xiao He Research Farm, Pan Long District $25.176593^{\circ} \mathrm{N}, 102.794697^{\circ} \mathrm{E}, 2209 \mathrm{~m}$ asl, October 2014, from banana trap, EGWY41 (Wang Yan) USNMENT00896639; 1q, CHINA, Kunming, Xiao He Research Farm, Pan Long District $25.176593^{\circ} \mathrm{N}, 102.794697^{\circ} \mathrm{E}, 2209 \mathrm{~m}$ asl, 20 May 2014, from banana trap, EGWY87 (Wang Yan) USNMENT00896644; 1, CHINA, Kunming, Xiao He Research Farm, Pan Long District $25.176593^{\circ} \mathrm{N}, 102.794697^{\circ} \mathrm{E}, 2209 \mathrm{~m}$ asl, 20 July 2015, from banana trap, EGWY103 (Wang Yan) SEM USNMENT01525765; 1, CHINA, Kunming, Xiao He Research Farm, Pan Long District $25.176593^{\circ} \mathrm{N}, 102.794697^{\circ} \mathrm{E}, 2209 \mathrm{~m}$ asl, 20 July 2015, from banana trap, EGWY135 (Wang Yan) USNMENT00896648; 1, CHINA, Kunming, Xiao He Research Farm, Pan Long District $25.176593^{\circ} \mathrm{N}, 102.794697^{\circ} \mathrm{E}, 2209 \mathrm{~m}$ asl, 20 July 2015, from banana trap, EGWY137 (Wang Yan) USNMENT00896633; 19, CHINA, Kunming, Xiao He Research Farm, Pan Long District 25.176593 $\mathrm{N}, 102.794697^{\circ} \mathrm{E}, 2209 \mathrm{~m}$ asl, 20 July 2015, from banana

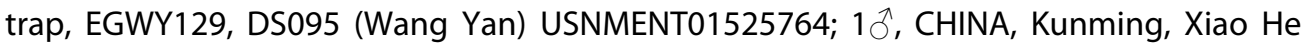
Research Farm, Pan Long District $25.176593^{\circ} \mathrm{N}, 102.794697^{\circ} \mathrm{E}, 2209 \mathrm{~m}$ asl, 20 July 2015, from banana trap, EG15CZ6R BT-26, DSZ102 (Wang Yan) USNMENT01525761; 1 , , CHINA, Kunming, Xiao He Research Farm, Pan Long District $25.176593^{\circ} \mathrm{N}, 102.794697^{\circ} \mathrm{E}, 2209 \mathrm{~m}$ asl, 20 July 2015, from banana trap, EG15CZ6R-BT, DS194 (Wang Yan) USNMENT01525762; 19, CHINA, Kunming, Xiao He Research Farm, Pan Long District $25.176593^{\circ} \mathrm{N}, 102.794697^{\circ}$ E, 2209 m asl, 20 May 2015, from banana trap, EGWY119 (Wang Yan) USNMENT00896626; 1 , , CHINA, Kunming, Xiao He Research Farm, Pan Long District $25.1178^{\circ} \mathrm{N}, 102.4842^{\circ} \mathrm{E}, 23$ June 2015, from banana trap, EG15CZ6RBT-19 (E. Guerrieri, M. Giorgini, K. Hoelmer) USNMENT00896625; 1으. CHINA, Kunming, Xiao He Research Farm, Pan Long District $25.112378{ }^{\circ} \mathrm{N}, 102.481742^{\circ} \mathrm{E}, 23$ June 2015, from banana trap, EG15CZ6RBT-27 (Wang Yan) USNMENT00896628; 1 , CHINA, Kunming, Xiao He Research Farm, Pan Long District 25.112378 $\mathrm{N}, 102.481742^{\circ} \mathrm{E}, 23$ June 2015, from banana trap, EGCZ6RBTR19-4 (Wang Yan) USNMENT00896627; 1 , , CHINA, Kunming, Kunming Botanical Gardens, Pan Long District, $25.145348^{\circ} \mathrm{N}, 102.741543^{\circ} \mathrm{E}, 1958 \mathrm{~m}$ asl, 12 July 2015, from blackberry fruits, EG15CZ5-6 (Wang Yan) USNMENT00896638; $1 \hat{\jmath}$, CHINA, Kunming, Kunming Botanical Gardens, Pan Long District, $25.145348^{\circ} \mathrm{N}, 102.741543^{\circ} \mathrm{E}, 1958 \mathrm{~m}$ asl, 12 July 2015, from blackberry fruits, EG15CZ5-23, DSZ 184 (Wang Yan) USNMENT01525763; 1, CHINA, Kunming, Kunming Botanical Gardens, Pan Long District, $25.145348^{\circ} \mathrm{N}, 102.741543^{\circ} \mathrm{E}, 1958 \mathrm{~m}$ asl, 12 July 2015, from blackberry fruits, EG15CZ5-32 (Wang Yan) USNMENT00896620; 1 , , CHINA, Kunming, Kunming Botanical Gardens, Pan Long District, 25.145348 ${ }^{\circ}$, $102.741543^{\circ} \mathrm{E}, 1958 \mathrm{~m}$ asl, 12 July 2015, from blackberry fruits, EG15CZ5-34 (Wang Yan) USNMENT00896649; 1 , CHINA, Kunming, Cheng Jiang County, Long Jie Zuo Suo Cun, $24.711991^{\circ} \mathrm{N}, 102.870912^{\circ}$ E, 2053 m asl, 24 July 2013, from banana trap, EGCZ1BTR2-2 (E. Guerrieri, M. Giorgini, K. Hoelmer) USNMENT00896624; 19 , CHINA, Kunming, Cheng Jiang County, Long Jie Zuo Suo Cun, $24.711991^{\circ} \mathrm{N}, 102.870912^{\circ} \mathrm{E}, 2053 \mathrm{~m}$ asl, 24 July 2013, from banana trap, EGCZ1BTR2-3 (E. Guerrieri, M. Giorgini, K. Hoelmer) USNMENT00896647; 19, CHINA, Kunming, Cheng Jiang County, Fu Xian Lake, $24.506364^{\circ} \mathrm{N}, 102.860508^{\circ} \mathrm{E}, 1759 \mathrm{~m}$ asl, 24 July 2013, from banana trap, EGCZ2BTR4-2 (E. Guerrieri, M. Giorgini, K. Hoelmer) USNMENT00896635; 4ㅇ 6 $\overbrace{}^{\AA}$, CHINA, Yunnan Prov., Fumin, $25.1475^{\circ} \mathrm{N}, 102.5289^{\circ}$, ex D. suzukii or D. pulchrella on Myrica rubra, 7 February 2016, Jinping Zhang (CABI2)

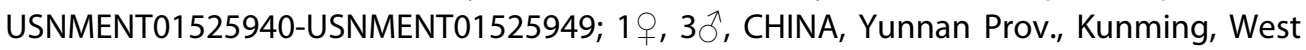


Mountain, $25.1475^{\circ} \mathrm{N}, 102.5289^{\circ} \mathrm{E}$, ex D. suzukii on Myrica rubra, 7.II.2016, Fang Huan/Wu Hao (CABI3) USNMENT01525936-USNMENT01525939.

Biology. Reared from Drosophila suzukii or D. pulchrella on Myrica rubra (CABI specimens). Other specimens were collected in the wild with banana-baited traps from May to October, with the majority in July (USNMENT00896649 emerged from blackberries). Banana traps were set up in wild vegetation in natural reserves (Kunming, Cheng Jiang County, Long Jie Zuo Suo Cun), in natural habitats surrounding orchards (Kunming, Xiao He Research Farm, Pan Long District), in blueberry crops (Kunming, Cheng Jiang County, Fu Xian Lake), and in a botanical garden (Kunming Botanical Gardens, Pan Long District).

Comments. Leptopilina lasallei possesses some unusual character states for members of Leptopilina. Using van Noort et al. (2015), male L. lasallei runs to Leptopilina; a female specimen may also run to Leptopilina after some hesitation, but an often relied upon character, the 'broken' or 'interrupted' metasoma hairy ring character state, is not present. Instead, the hairy ring is complete in the females of L. lasallei, and this may add some confusion to diagnosing this taxon. In fact, this dimorphism is stronger than in most Eucoilinae, and interestingly, the pattern is inverted compared to other Leptopilina where the hairy ring of the female is more reduced than that of the male. This switch in dimorphism begs for clarifying observations of the behaviour of live specimens and the physiology of this trait.

Leptopilina is one of the better studied genera of Eucoilinae, with laboratory strains genetically and behaviourally studied, and a relatively large number of species that have been described or redescribed in modern times. Nevertheless, a large portion of worldwide diversity is still unaccounted for.

Leptopilina often gets confused with other small drosophilid parasitoids such as Ganaspis (Ganaspini) and Hexacola (Ganaspini) but is easily recognised by the characters that reveal its belonging in Eucoilini rather than Ganaspini: F2 in male antennae equally or more modified (curved/excavated/elongated) than F1, glabrous and more or less oblique posteroventral corner of metapleuron. Furthermore, Leptopilina are characterised by a well-developed petiolar rim. The setal bands ('hairy ring') of the base of the metasoma are often reduced to varying extents. In a few species, female flagellomere number is reduced to 10 . Most but not all species have a high, convex scutellum. These additional characters commonly occur among the genera of Ganaspini but distinguish Leptopilina from most of its closer relatives within the Eucoilini.

Within Leptopilina, two species that L. lasallei can be confused with are L. decemflagella and L. tsushimaensis, as females in both of these species have 10 flagellomeres in their antennae (Lue et al., 2016). However, L. decemflagella and L. tsushimaensis females both have incomplete hair rings at the base of their metasoma. The striate dorsal surface of the scutellum in $L$. lasallei is shared with L. freyae and L. boulardi (Allemand et al., 2002); again, the latter two have a metasomal hairy ring in the female which is more or less strongly reduced (incomplete or even absent); male $L$. lasallei have the F1 and F2 of the antennae equal in size, whereas in in $L$. freyae and $L$. boulardi, $\mathrm{F} 2$ is clearly longer than F1. Another useful character for distinguishing $L$. lasallei from $L$. freyae and L. boulardi, and from $L$. orientalis which is similar too, is the shape of the propodeal carinae: in L. lasallei, these are heavily sclerotised and thick, overall lyre-shaped; 
in the other species of Leptopilina that are overall similar looking, the propodeal carinae are finer, less massive and parallel sided.

\section{Phylogenetic reconstruction}

Bayesian analysis of the concatenated COI, 28S D2 and ITS2 data set produced a tree that highly supports the sister-group relationship of $L$. lasallei and the remaining species of Leptopilina (Figure 12). Five highly supported species groups were identified within the Leptopilina clade. While the lasallei and boulardi groups each have a single species in the current analysis, the clavipes, decemflagella and heterotoma groups include species from different continents.

\section{Discussion}

The new species clearly ended up as the sister group of the other Leptopilina species included, constituting the vast majority of the better known species. Thus, an argument could be made to either erect a new genus for lasallei or to somewhat expand the concept of Leptopilina. Since it is uncertain where many less-known species of Leptopilina as well as many undescribed species would end up in this phylogeny, it has been deemed best to pursue with caution. Thus, we recommend waiting to erect new genera until more species have been accounted for, especially to the extent they are intermediate between typical Leptopilina and related genera such as Linaspis and Maacynips, genera which are very poorly known at this stage, and in which most species remain undescribed (Forshage and Buffington, pers. obsv.).

The COI, 28S D2 and ITS2 molecular data sets recovered L. lasallei as sister group to Leptopilina. Clearly, more molecular data beyond these three gene fragments are needed to infer evolutionary trends; however, the phylogeny presented here is the most comprehensive in terms of the taxon sampling of Leptopilina since Allemand et al. (2002) and Novković et al. (2011). Allemand et al. (2002) suggested species groups for African Leptopilina, and in the data presented here, these groups appear to be supported. The lasallei and boulardi groups are each represented in our study by a single species only, but are both clearly distinct lineages from the rest of Leptopilina species (Figure 4), and sister groups to the remaining Leptopilina. Our data suggest expanding the heterotoma group to include additional Asian species, namely L. ryukuensis, $L$ japonica and $L$. pacifica. Two new species groups emerged from our concatenated data set (Figure 4): the clavipes group (L. clavipes, L. leipsi, L. maia, L. freyae and L. orientalis) and the decemflagella group ( $L$. decemflagella and $L$. tsushimaiensis). The clavipes group is not clearly delineated, and this was already discussed in Lue et al. (2016). It should be noted that Allemand et al. (2002) recovered $L$. freyae and $L$. orientalis in the boulardi group; we speculate that our expanded data set in terms of taxon sampling is responsible for this difference.

The decemflagella group shows a remarkable amount of sequence divergence (Figure 4). In fact, this is the most divergent among eucoilines sampled here, and certainly warrants future investigation. The need for further work in decemflagella is underscored by the fact that the sister group is tsushimaensis. Additional data may suggest these two names be synonymised, but at the present, we prefer to keep them as distinct species. 
The groups of Allemand et al. (2002) and our study (presented here) largely reflect the topologies presented in Novković et al. (2011), although the taxon sampling of the latter was restricted to heterotoma-group species from Japan. Groups I-V from Novković et al. (2011) are contained within our heterotoma group of species, with a key difference in the placement of $L$. pacifica. In our study, L. pacifica is sister group to L. heterotoma plus the remaining species; in Novković et al. (2011), L. heterotoma comprises Group V and is sister group to the remaining Leptopilina. Some differences between our study and that of Novković et al. (2011) are our more robust taxon sampling, a more suitable out-group taxon and differences in tree-building methods [Bayesian analysis in our case; neighbour joining in Novković et al. (2011)].

Morphological and molecular data produced in this work, other than adding new information on taxonomy of drosophilid parasitoids, may help biological control practitioners to identify and select potential biocontrol agents. In terms of future directions, we are currently analysing ultra-conserved element phylogenomic data (Blaimer et al. 2016) for both Cynipoidea and Hymenoptera as a whole (in prep.). The goal is to evaluate these data for cryptic species and discrimination of closely related species in parasitoids. Currently, data on bees (Blaimer et al. 2016; Bossert et al. 2019) indicate that these data are suitable for species discrimination, and we plan to have diagnostic data for both Leptopilina and Ganaspis species in the near future, a fundamental step for their use in biocontrol programmes against destructive pest species.

\section{Acknowledgements}

Yan Wang, Fu-Shou Chen, Hong-Mei Zhang, Zong-Qi Chen (YAAS, China) Hong-Yin Chen, Chen-Xi Liu (CAAS, China) Xin-Geng Wang, Kim Hoelmer and Kent M. Daane (USDA) are thanked for their collaboration in field collections. We also thank Marc Kenis and Pierre Girod (CABI) for allowing the inclusion of their rearings in this description. MB would like to personally thank Marc Kenis for his insight connecting CABI 'Leptopilina sp' with the other specimens used in this study; thanks Marc! Simona Carpenito (IPSP-CNR) is thanked for helping sequence the material examined. EG and MG were funded by the UE FP7/2007-2013 project ASCII under grant agreement PIRSES-GA-2012318246; MB was funded by the Systematic Entomology Laboratory, ARS-USDA. Mention of trade names or commercial products in this publication is solely to provide specific information and does not imply recommendation or endorsement by the USDA. USDA is an equal opportunity provider and employer.

\section{Author contributions}

Conceived the project: $\mathrm{EG}, \mathrm{MB}$

Wrote the initial manuscript: $M B, E G$

Edited and revised the manuscript thereafter: MG, MF, MB

Sampled and sorted parasitoids in China: EG, MG

Conducted the taxonomic work: $\mathrm{MB}, \mathrm{EG}, \mathrm{MF}, \mathrm{CL}$

Carried out molecular characterisation and phylogenetic analysis: MB, MG, PC, GF, AD

All authors read and approved the manuscript.

\section{Disclosure statement}

No potential conflict of interest was reported by the authors. 


\section{ORCID}

Matthew L. Buffington (iD http://orcid.org/0000-0003-1900-3861

Massimo Giorgini (D) http://orcid.org/0000-0001-8670-0945

Chia-Hua Lue (D) http://orcid.org/0000-0002-5245-603X

Pasquale Cascone (D) http://orcid.org/0000-0002-4097-1974

Emilio Guerrieri (D) http://orcid.org/0000-0002-0583-4667

\section{References}

Allemand R, Lemaître C, Frey F. 2002. Phylogeny of six African Leptopilina species (Hymenoptera: Cynipoidea, Figitidae), parasitoids of Drosophila, with description of three new species. Ann Soc Entomol Fr. 38:319-332. doi:10.1080/00379271.2002.10697346

Blaimer B, Lloyd M, Guillory W, Brady S. 2016. Sequence capture and phylogenetic utility of genomic ultraconserved elements obtained from pinned insect specimens. PLoS One. 11:e0161531. doi:10.1371/journal.pone.0161531

Bossert S, Murray EA, Almeida EAB, Brady SG, Blaimer BB, Danforth BN. 2019. Combining transcriptomes and ultraconserved elements to illuminate the phylogeny of Apidae. Mol Phylogenet Evol. 130:121-131. doi:10.1016/j.ympev.2018.10.012

Buffington ML, Nylander JAA, Heraty J. 2007. The phylogeny and evolution of Figitidae (Hymenoptera: Cynipoidea). Cladistics. 23:1-29. doi:10.1111/j.1096-0031.2007.00153.x

Campbell B, Heraty J, Rasplus JY, Chan K, Steffen-Campbell J, Babcock C. 2000. Molecular systematic of the Chalcidoidea using 28S-rDNA. In: Austin A, Dowton M, editors. The hymenoptera: evolution, biodiversity and biological control. Collingwood (Australia):CSIRO Publishing; p. 59-73.

Daane KM, Wang X-G, Biondi A, Miller B, Miller JC, Riedl H, Shearer PW, Guerrieri E, Giorgini M, Buffington M, et al. 2016. First exploration of parasitoids of Drosophila suzukii in South Korea as potential classical biological agents. J Pest Sci. 89:643-651. doi:10.1007/s10340-016-0757-4

Farnsworth D, Hamby KA, Bolda M, Goodhue RE, Williams JC, Zalom FG. 2017. Economic analysis of revenue losses and control costs associated with the spotted wing drosophila, Drosophila suzukii (Matsumura), in the California raspberry industry. Pest Manag Sci. 73:1083-1090. doi:10.1002/ps.4497

Folmer O, Black M, Hoeh W, Lutz R, Vrijenhoek R. 1994. DNA primers for amplification of mitochondrial cytochrome $\mathrm{c}$ oxidase subunit I from diverse metazoan invertebrates. Mol Mar Biol Biotechnol. 3:294-299.

Forshage M. 2008. Systematics of Eucoilini [Doctoral Dissertation]. Sweden: Faculty of Science and Technology. Univ, 679. Uppsala University; p. 59.

Gates M, Buffington ML. 2011. Description of two techniques to increase efficiency in processing and curating minute arthropods, with special reference to parasitic Hymenoptera. J Hymenopt Res. 22:29-43. doi:10.3897/jhr.22.2099

Giorgini M, Wang XG, Wang Y, Chen FS, Hougardy E, Zhang HM, Chen ZQ, Chen HY, Liu CX, Cascone $P$, et al. 2019. Exploration for native parasitoids of Drosophila suzukii in China reveals a diversity of parasitoid species and host specificity of the dominant parasitoid. J Pest Sci (2004). 92:509-522. doi:10.1007/s10340-018-01068-3

Girod P, Borowiec N, Buffington ML, Chen G. 2018. The parasitoid complex of D. suzukii and other fruit feeding Drosophila species in Asia. Sci Rep. 8:11839. doi:10.1038/s41598-018-29555-8

Guerrieri E, Giorgini M, Cascone P, Carpenito S, van Achterberg C. 2016. Species diversity in the parasitoid genus Asobara (Hymenoptera: Braconidae) from the native area of the fruit fly pest Drosophila suzukii (Diptera: Drosophilidae). PLoS One. 11:e0147382. doi:10.1371/journal. pone.0147382

Hebert P, Penton EH, Burns JM, Janzen DH, Hallwachs W. 2004. Ten species in one: DNA barcoding reveals cryptic species in the neotropical skipper butterfly Astraptes fulgerator. Proc Natl Acad Sci. 101:14812-14817. doi:10.1073/pnas.0406166101 
Hebert PDN, Ratnasingham S, Zakharov EV, Telfer AC, Levesque-Beaudin V, Milton MA, Pedersen S, Jannetta P, deWaard JR. 2016. Counting animal species with DNA barcodes: Canadian insects. Phil. Trans. R. Soc. B. 371:20150333. doi:10.1098/rstb.2015.0333

Hebert PDN, Ratnasingham S, Zakharov EV, Telfer AC, Levesque-Beaudin V, Milton MA, Pedersen S, Jannetta P, DeWaard JR. 2013. Barcoding Canada Data.

Kacsoh BZ, Schlenke TA. 2012. High hemocyte load is associated with increased resistance against parasitoids in Drosophila suzukii, a relative of D. Melanogaster. Plos ONE. 7(4):e34721. doi:10.1371/journal.pone.0034721

Lee JW, Choi WY. 1993. A systematic study of the superfamily Cynipoidea (Hymenoptera) from Korea I. Family Eucoilidae. Entomol Res Bull. 19:45-54.

Lee M, Kalamarz M, Paddibhatla I, Small C, Rajwani R, Govind, Shubha. 2009. Virulence Factors and Strategies of Leptopilina spp.: selective Responses in Drosophila Hosts. In: Prévost G, editor. Advances in Parasitology, Vol. 70. Burlington: Academic Press; p. 123-145. ISBN: 978-0-12374792-1.

Lin K. 1988. The Eucoilidae from Taiwan, I. (Hymenoptera: Cynipoidea). J Natl Taiwan Mus. 41:1-66.

Lue CH, Driskell AC, Leips J, Buffington ML. 2016. Review of the genus Leptopilina (Hymenoptera, Cynipoidea, Figitidae, Eucoilinae) from the Eastern United States, including three newly described species. J Hymenopt Res. 53:35-76. doi:10.3897/jhr.53.10369

Maddison WP, Maddison DR. 2019. Mesquite: a modular system for evolutionary analysis. Version, 3.61. http://www.mesquiteproject.org

Nomano FY, Kasuya N, Matsuura A, Suwito A, Mitsui H, Buffington ML, Kimura MT. 2017. Genetic differentiation of Ganaspis brasiliensis (Hymenoptera: Figitidae) from East and Southeast Asia. Appl Entomol Zool. 52:429-437. doi:10.1007/s13355-017-0493-0

Nordlander G. 1980. Revision of the genus Leptopilina Förster, 1869, with notes on the status of some other genera (Hymenoptera, Cynipoidea: Eucoilidae). Entomol Scand. 11:428-453. doi:10.1163/ 187631280794710024

Novković B, Mitsui H, Suwito A, Kimura MT. 2011. Taxonomy and phylogeny of Leptopilina species (Hymenoptera: Cynipoidea: Figitidae) attacking frugivorous drosophilid flies in Japan, with description of three new species. Entomol Sci. 14:333-346. doi:10.1111/j.1479-8298.2011.00459.x

Schilthuizen M, Nordlander G, Stouthamer R, van Alphen J. 1998. Morphological and molecular phylogenetics in the genus Leptopilina (Hymenoptera: Cynipoidea: Eucoilidae). Syst. Entomol. 23:253-264. doi:10.1046/j.1365-3113.1998.00049.x

Stouthamer R, Hu J, Frenk JPM van Kan, Platner G, Pinto J. 1999. The utility of internally transcribed spacer 2 DNA sequences of the nuclear ribosomal gene for distinguishing sibling species of Trichogramma. BioControl. 43:421-440. doi:10.1023/A:1009937108715

Van Alphen J, Nordlander G, Eijs I. 1991. Host habitat finding and host selection of the Drosophilaparasitoid Leptopilina australis (Hymenoptera, Eucoilidae), with a comparison of the niches of European Leptopilina species. Oecologia. 87:324-329. doi:10.1007/BF00634586

van Noort S, Buffington ML, Forshage M. 2015. Afrotropical Cynipoidea (Hymenoptera). ZooKeys. 493:1-176. doi:10.3897/zookeys.493.6353

Vass E, Nappi AJ. 2000. Developmental and immunological aspects of Drosophila - parasitoid relationships. J Parasitol. 86(6):1259-1270. doi:10.1645/0022-3395(2000)086[1259:DAIAOD]2.0. $\mathrm{CO} ; 2$

Wachi N, Nomano FY, Mitsui H, Kasuya N, Kimura MT. 2015. Taxonomy and evolution of putative thelytokous species of Leptopilina (Hymenoptera: Figitidae) from Japan, with description of two new species. Entomol Sci. 18:41-54. doi:10.1111/ens.12089

Yoshimoto C. 1962. Insects of Micronesia: hymenoptera: eucoilinae (Cynipoidea). Insects Micronesia. 19:89-107.

Yoshimoto C, Yasumatsu K. 1965. The Eucoilinae of the Ryukyu Archipelago. Pac Insects. 7:643-660. 